\title{
Foot Drop following Neuraxial Anaesthesia: A Case Report
}

\author{
Nitu Puthenveettil ${ }^{*}$, Jerry Paul ${ }^{2}$, Sunil Rajan 3 , Lakshmi Kumar ${ }^{4}$ \\ ${ }^{1}$ Associate Professor, ${ }^{2,3,4}$ Professor, Department of Anesthesia and Critical care, Amrita Vishwa \\ Vidyapeetham, Amrita Institute of Medical Sciences, Kochi, Kerala, India.
}

\begin{abstract}
Neurological complications during neuraxial anaesthesia are rare but if they occur, the consequences are disastrous. In most cases, it is difficult to identify the exact aetiology. For a good recovery, early diagnosis and intervention should be ensured. We report a case of foot drop following possible needle trauma in a patient who underwent total abdominal hysterectomy under combined spinal-epidural technique.
\end{abstract}

Key words: anaesthesia, complication, regional, foot drop, hysterectomy

\section{Introduction}

Neurologic complications following regional anaesthesia are rare with an incidence of 1 in 10,000 cases. $^{1,2}$ If a patient complains of severe pain or paraesthesia while performing regional anaesthesia, neurological deficits in the postoperative period should be anticipated. The neurological damage could be attributed to direct trauma, epidural haematoma or chemical irritation. We report a case of foot drop following possible needle trauma in a patient who underwent total abdominal hysterectomy under combined spinal-epidural technique.

\section{Case report}

A 67-year-old lady, with an ovarian mass was posted for total abdominal hysterectomy with bilateral salphingo-oophorectomy. She had been disoriented for the previous 3-4 days. Routine pre-op investigations revealed a sodium of 118 $\mathrm{m} \mathrm{Eq} / \mathrm{L}$ and correction with $3 \%$ sodium chloride was started. On the day of surgery she was asymptomatic with a repeat sodium of $126 \mathrm{mEq} / \mathrm{L}$. After attaching monitors, she was sedated with intravenous midazolam $2 \mathrm{mg}$. Under strict asepsis and local anaesthetic infiltration, a combined spinal-epidural was

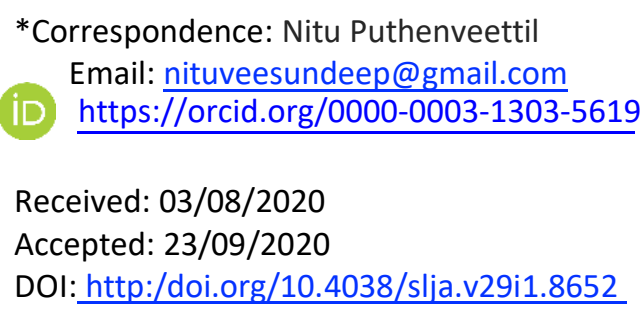

Received: 03/08/2020

Accepted: 23/09/2020

DOI: http:/doi.org/10.4038/slja.v29i1.8652

placed in the left lateral position. Epidural at T11-12and subarachnoid block was given in L3L4 space with $3 \mathrm{ml}$ of $0.5 \%$ heavy bupivacaine and $10 \mu \mathrm{g}$ fentanyl. The patient was asymptomatic and deeply sedated during the procedure. She was later placed supine when she complained of some discomfort and breathlessness. She was reassured and $20 \mu \mathrm{g}$ of intravenous fentanyl was given after which she seemed to be comfortable. After one hour, epidural infusion of $0.5 \%$ bupivacaine was started at $5 \mathrm{ml} / \mathrm{hr}$. Surgery lasted for 2 hours. Post operatively epidural infusion was stopped and patient was shifted to the recovery room. In the recovery, she complained of paraesthesia and weakness of the left leg. She had intense shooting pain in her left lower limb below her knees even at rest and also complained of increased bladder frequency and incomplete evacuation. A neurology consultation was sought. Physical examination showed that there was motor deficit in the left knee and ankle (4/5 and $3 / 5$ respectively) with no sensory deficit. Left knee jerk was absent and ankle jerk was brisk. An MRI spine was taken which showed swollen conus with abnormal bright signals probably due to oedema. She was started on methylprednisolone $1 \mathrm{gm}$ IV once daily for 5 days and gabapentin 100mg 8th hourly to combat the pain. Physiotherapy was also initiated. On the second postoperative day, she was able to walk but with a high stepping gait of the left leg. The intravenous steroid was tapered to oral prednisolone. The patient gradually improved and was discharged on postoperative day11. She continued physiotherapy at home and reported to us at 4 weeks and then at 6 months. She had partial recovery with mild weakness on dorsiflexion of the left foot. All 
other movements were normal and there was no sensory loss.

\section{Discussion}

Neurological complications following regional anaesthesia are rare. Needle trauma and local anaesthetic toxicity following spinal anaesthetic arereported. ${ }^{3,4}$ In a majority of patients it is difficult to pin point the exact aetiology. Cauda equina syndrome, spinal cord compression by epidural haematoma, epidural abscess and transient neurological symptoms are other causes of neurological damage. ${ }^{5-7}$

The orientation of the needle during epidural and spinal needle placement is an important factor in determining the extent of nerve injury. Transverse needle insertion is associated with greater nerve injury than horizontal insertion and is better avoided. ${ }^{2}$ Paraesthesia while performing neuraxial anaesthesia may be due to direct trauma to nerve roots or spinal cord. As there are no nerve roots posteriorly in the epidural space, cord penetration should be suspected if the patient complains of paraesthesia. ${ }^{3}$ Severe burning pain in the lower back and extremities along with bladder and bowel dysfunction are associated with direct trauma to the spinal cord. To limit the neurological damage, lower lumbar epidurals should be preferred over upper lumbar and thoracic epidurals. High thoracic epidurals should be performed only by an experienced anaesthetist.

Damage to the common peroneal nerve, sciatic nerve, L5 radiculopathy or lumbosacral plexus can also present as foot drop. If magnetic resonance imaging(MRI) is normal, nerve conduction and electromyogram (EMG)is required to localize the site of the lesion. ${ }^{5,8}$ In our case, EMG was not done as MRI showed conus lesions. The epidural or spinal needle may accidentally touch the nerve roots or injure the spinal cord. Our patient was very frail and the distance from the skin to the spinal cord was only $3.76 \mathrm{~cm}$.[Fig1] Hence trauma could be produced by even the $24 \mathrm{G}$ needle used to administer local anaesthestics (usually $4 \mathrm{~cm}$ long). Neurological complications from direct injury to the spinal cord by the $24 \mathrm{G}$ needle could be avoided by not infiltrating local anaesthetic beyond the subcutaneous tissue and by stopping injection of the drug and withdrawing the needle if the patient complains of paresthesia during the procedure. Intensity of paraesthesia may serve as a guide for severity of nerve injury. ${ }^{8}$ Our patient did not complain of pain during the procedure as midazolam along with fentanyl in a frail patient could have resulted in deep sedation.

\section{Conclusion}

No anaesthetic technique is entirely free of risk or injury. Hence during the neuraxial technique, the spinal and epidural needles must be inserted gently and withdrawn if the patient complains of paresthesia. In case of any neurological complains, urgent neurology consultation with imaging and treatment with steroids and physiotherapy is crucial to improve long term outcomes.

\section{References}

1. Rege DSA, Navarange DS, Rohondia DO. Complete flaccid paralysis following spinal anaesthesia - a case report Indian J. Anaesth. 2002; 46: 58-60.

https://doi.org/10.4103/0019-5049.162992

2. Aycan IO, Turgut H, Guzel A, Dogan E, Kavak GO. Foot drop following spinal anaesthesia. Braz J Anesthesiol. 2015;65:423-4. https//doi.org/10.1016/j.bjane.2014.06.003 MID: 26323747

3. Rastogi S, Bhandari R, Sharma V, Pandey T. Neurological complications following spinal anaesthesia in a patient with congenital absence of lumbar vertebra. Indian J Anaesth. 2014; 58:484. https://doi.org/10.4103/0019-5049.139021

4. Dastkhosh A, Razavi M, Gilani MT. Foot drop after spinal anesthesia for caesarean section: a case report. Local and Regional Anesthesia 2018;11: 45-47.

https://doi.org/10.2147/Ira.s165587 PMID: 30127636

5. Goyal VK, Mathur V. Foot drop: an iatrogenic complication of spinal anesthesia. Rev Bras Anestesiol. 2018;68:412-415.

https://doi.org/10.1016/j.bjane.2017.09.006 PMID: 29373140

6. Jadon A. Complications of regional and general anaesthesia in obstetric practice. Indian J Anaesth. 2010; 54:415.

https://doi.org/10.4103/0019-5049.71039 PMID: 21189879

7. Agarwal A, Kishore K. Complications and controversies of regional anaesthesia: A Review. Indian J Anaesth.2009; 53:543-553. https://doi.org/10.4103/0019-5049.71039 PMID: 20640104

8. Nirmala BC, Kumari G. Foot drop after spinal anaesthesia: a rare complication. Indian J Anaesth 2011; 55:78-9. https://doi.org/10.4103/0019-5049.76590 PMID: 21431063 